Research Article

\title{
Metacognitive thinking skills among talented science education students
}

\author{
Mohammad Al-Gaseem12, Bakkar Bakkar 3*, Suhail Al-Zoubi
}

College of Education, Sultan Qaboos University, Oman

\section{Article Info}

Received: 10 March 2020

Revised: 20 May 2020

Accepted: 02 June 2020

Available online: 15 June 2020

Keywords:

Cognitive processing

Metacognitive thinking skils

Talented students

Teacher education

2149-360X/ (C) 2020 The Authors. Published by Young Wise Pub. Ltd. This is an open access article under the CC BY-NC-ND license

\begin{abstract}
Metacognitive thinking skills in teacher education is very important. Therefore, it is important to focus on understanding education instead of memorization, using knowledge, solving problems related to new situations, being able to explain, synthesize and generalize and develop hypotheses. The purpose of this research was to examine the level of metacognitive thinking skills (MTSs) among talented science education students (TSESs) at Sultan Qaboos University (SQU), Oman. A purposeful sample of 77 TSESs was used to achieve this goal. The TSESs are registered in the Bachelor of Science Education program, and they have a high academic achievement. The TSESs responded to Omani Metacognitive Thinking Scale. This scale consists of 42 items distributed into three domains: Knowledge of cognition, regulation of cognition, and cognitive processing. The results indicated that TSESs possessed a high level of MTSs.
\end{abstract}

\section{To cite this article:}

Al-Gaseem, M., Bakkar, B., \& Al-Zoubi, S. (2020). Metacognitive thinking skills among talented science education students. Journal for the Education of Gifted Young Scientists, 8(3), 897-904. DOI: http://dx.doi.org/10.17478/jegys. 707205

\section{Introduction}

It is said that the human's cognitive development can be shaped and crystallized by self-understanding, selfknowledge, and self-reflection. Through self-reflection, individuals can scrutinize new concepts, compare them to prior knowledge, and create a set of new ideas. This form of self-reflection will generate new knowledge and new learning experiences (Tarricone, 2011). Metacognition is theoretically based on Self-regulated Learning Theory (SRLT) which has a distinguished history in social-cognitive learning theory (Tortop, 2015). The importance of selfefficacy as a cognitive construct is in that it can be applied to different cognitive and intellectual concepts and abilities. One of SRLT components that deserve in-depth investigation is metacognition. The SRLT helped to imply metacognition in learning and teaching process.

Metacognition is a higher order thinking which plays a crucial role in learning and teaching practices at education system (Karaduman \& Erbas, 2017). Metacognition refers to both people's awareness and control, not only of their cognitive processes, but of their emotions and motivations (Louca, 2003). Specifically, Flavell is one of the first theorists who put forward definition of metacognition. He classified metacognition into metacognitive knowledge, metacognitive experience, and metacognitive monitoring and control (Efklides, 2006). It is assumed that effective control of learning cannot occur in the absence of accurate monitoring. Metacognitive skills need high intellectual abilities exceeding limits of tangible thinking; that is these skills most likely exist in gifted and talented students.

Metacognition includes two kinds of higher order thinking: knowledge of cognition and regulation of cognition (Ma \& Baranovich, 2015). Knowledge of cognition refers to what we know about our cognition and about their thinking and learning. It consists of declarative knowledge, procedural knowledge, and conditional knowledge (Schraw et al. 2006). Meanwhile, regulation of cognition typically comprises planning, monitoring and evaluation 
skills (Schraw, 1998). In short, knowledge of cognition refers to knowing about our thinking, but regulation of cognition refers to actively guiding our thinking (Young \& Worrell, 2018). Jia et al. (2019) explains that metacognition refers to the knowledge and regulation of one's own cognitive processes, which has been regarded as a critical component of creative thinking.

On the other hand, Schwartz and Perfect (2002) identified metacognition components into metacognitive knowledge and metacognitive awareness. Metacognitive knowledge refers to knowledge about cognitive strengths and weaknesses, but metacognitive awareness refers to feelings and experiences that materialize before, during, and after cognitive activities have been performed. Metacognition is important in self-regulatory learning; because it strongly affects the learner's motivation. There are two ways in which metacognition can influence motivation, and through it, self-regulation of behavior. First, through its effects on self-processes and, second, through its effects on causal attributions (Efklides, 2009).

Countries give universities a prestigious place due to their effective role in generating, developing and renewing human knowledge as well as preparing specialists, researchers and scholars. This role gave the universities an opportunity to lead the epistemic revolution that contributed to the development of human societies. Universities historically existed as educational institutions to create and spread knowledge. University teaching is not just mere lecturing and cramming or transferring information, but a holistic process to develop students' cognitive, social and personal aspects. The role of universities revolves around providing students with thinking skills. The transition of these students from acquiring knowledge to its production is one of the university tasks. This can be done by improving cognitive and MTSs of university students.

University students acquire new knowledge in several academic fields over a condensed time. The successful ones of them learn to modify their knowledge as facts or perspectives that can be learnt (Everson \& Tobias, 1998). Therefore, metacognition becomes more significant for identifying gifted and talented students and supporting their learning, especially they use this skill efficiently to learn science and solve science problem (Ucar, 2018). Gifted and talented students sometimes demonstrate more adept use of metacognition than their non-gifted age peers and sometimes they do not, if the tasks are too easy (Carr et al. 1996). Carr and Taasoobshirazi (2008) asserted that metacognition promotes efficient working memory of gifted and talented students.

Lestari et al. (2019) demonstrated the weakness of MTSs related to planning, monitoring and evaluation in understanding the scientific terms among university biology students. Rather, Pramusinta et al. (2019) indicated that teaching university courses according to discovery learning method by using cognitive styles improved critical and MTSs among undergraduate science students. Idawati et al. (2020) also found that teaching natural sciences course by problem-solving strategy and cognitive flexibility improved university students' metacognitive skills. Van der Stel and Veenman $(2008,2010)$ examined the relationship between metacognitive skilfulness and intellectual ability as predictors of learning performance in adolescents, they showed that metacognitive skilfulness contributed to learning performance and developed on both quantitative and qualitative levels of academic performance. Sternberg (2001) suggested gifted students develop expertise at a more rapid rate than average students; thus they should be more effective and efficient employers of metacognition. Intellectual maturity and metacognitive sophistication are two indicators of cognitive development in college students, yet little is known about the metacognitive development of them.

Academically talented students are a vital part of any university education system, so universities seek to take care of them and meet their diverse needs. SQU is one of the educational institutions in Oman that plays a role in developing students' personality and thinking. SQU contributes to help students to use effective cognitive strategies that have students acquire, assimilate, understand and recognize more difficult and abstract concepts by mainly relying on analyzing and criticizing conceptions. Moreover, improving pre-service teacher programs to include training in pedagogy is important to facilitate students' attainment of metacognitive skills. In particular, many teachers were not as confident of teaching science compared to other majors. This led researchers to explore the role of metacognitive thinking in developing pre-service talented science education student's performance to integrate their expertise into their science education. The program of science education at SQU includes diverse courses which are intended for developing metacognitive skills, such as: Science Teaching Methodology (1), Science Teaching Methodology (2), Mathematics Teaching Methodology (1), Mathematics Teaching Methodology (2), Educational psychology, learning theories, Thinking styles....etc. This research can provide scientific framework on metacognition and science education; because it is associated with other effective teaching strategies that will be imperative to improve learning outcomes in schools. TSESs are best targeted to be studied according to MTSs; 
because these skills can be seemingly developed in this category as a result of necessitating teaching abstract and scientific conceptions in science majors (Biology, Chemistry and Physics). In other words, the current research aims to identify determine level of MTSs among TSESs in SQU.

\section{Research Problem}

Nowadays teaching science and mathematics in schools in different study stages requires to developing styles of thinking which are based on analysis, reasoning and recognition. Scientific phenomena and mathematical problems need students to be more abstract and metacognitive. Accordingly, science and mathematics teachers are strongly interested in developing and strengthening these styles of thinking. It is supposed that these teachers should have high intellectual abilities to be able to deal with students in scientific and mathematical phenomena and problems. Consequently, higher education institutions have admission policies related to admitting students in colleges of science and mathematics within strict conditions. Outcomes of academic programs which are part of scientific colleges mainly focus on creating gifted graduates who demonstrate abilities to deeply analyze scientific phenomena, puzzles and problems, then to help students solve with difficulty or ingenuity. College of education can contribute to improving the quality of graduates by offering course on cognitive theory of learning which has principles and rules in the development of cognitive and metacognitive skills. Metacognitive skills are those ones required to be acquired by students in schools to enable them to deal with differently difficult scientific phenomena. The process of acquisition needs gifted, skilled and proficient teachers to help their students in schools. Thereupon, this study attempted to examine the level of metacognitive thinking skills (MTSs) among talented science education students (TSESs) at SQU. Specifically, the study addresses the following questions:

$>$ What is the level of MTSs among TSESs at SQU?

$>$ Are there significant differences in MTSs due to gender (Male, Female) and class standing (Junior, Senior)?

\section{Research Design}

\section{Methodology}

This research was a quantitative research with descriptive analytical approach. This approach used the survey method to identify the level of MTSs among TSESs at the College of Education, SQU.

\section{Participants}

A total of 77 TSESs (31 males and 46 females) were involved in this research. The TSESs are enrolled in the Bachelor of Science Education program at the College of Education in SQU, Oman. The TSESs chosen based on their higher academic achievement were 40 juniors and 37 seniors. There GPA ranged from 3.55 to 4.94 (excellent), according to SQU grading system in the second semester 2019/2020.

\section{Data Collection}

This research used the Jordanian Metacognitive Thinking Scale (JMTS). The JMTS had high reliability and validity coefficients (Al-Jarrah \& Obeidat, 2011). The JMTS included 42 items distributed into three domains: cognitive regulation, knowledge of cognition and cognitive process. To develop a modified version of the JMTS fitted with Omani university students, validity coefficients of modified version of scale were verified. The Omani Metacognitive Thinking Scale (OMTS) was revised by three faculty members at the College of Education, SQU. In addition, the correlation coefficient was also used. The OMTS was administered to 253 students at the College of Education in a pilot study. The correlation coefficients values for each domain items were as follows: Cognitive regulation (0.44 to 0.67 ), knowledge of cognition ( 0.53 to 0.72 ), and cognitive process ( 0.48 to 0.62 ).

Cronbach's Alpha formula was used to test the reliability. The coefficients of internal consistency of OMTS domains were as follows: Cognitive regulation (0.889), Knowledge of cognition (0.894), cognitive process (0.884) and the total (0.893). Therefore, the final version the OMTS consisted of 42 items distributed into three domains: cognitive regulation, knowledge of cognition and cognitive process. Moreover, each item of OMTS is responded based on a 5-point rating scale from always (5) to never (1). The maximum score of this scale is (210), the average score is (126), and the minimum score is (42). Each dimension of OMTS has 14 items, so the maximum score of each one is (70), the average is (42) and the minimum is (14). The following criterion was used to assess degree or level of the MTSs: low (1:00 to 2.33), moderate (2.34 to 3.67), and high (3.68 to 5:00).

\section{Results}


Results of this study were extracted from answering the following questions: What is the level of MTSs among TSESs at SQU? Are there significant differences in MTSs due to gender (male, female) and class standing (junior, senior)? To answer these questions, means, standard deviations and t-test were used. Means and standard deviations of scores of OMTS items were calculated as shown in Table 1.

Table 1.

Means and Standard Deviations of Scores of OMTS Items

\begin{tabular}{lcccccc}
\hline Dimension & N & M & SD & t & p & Level \\
\hline Cognitive Processes & 77 & 4.48 & 0.557 & 70.66 & 0.001 & High \\
Cognitive Regulation & 77 & 4.12 & 0.424 & 85.40 & 0.001 & High \\
Knowledge of Cognition & 77 & 3.61 & 0.884 & 35.88 & 0.001 & High \\
\hline Total & 77 & 4.16 & 0.321 & 113.8 & 0.001 & High \\
\hline
\end{tabular}

Table 1 showed mean of domains of OMTS ranged (3.61 and 4.48). One-sample t-test indicated that mean scores of MTSs for all dimensions and the total of OMTS were significant, $\mathrm{t}=$ (70.66), (85.40), (35.88), and (113.8) respectively, $\mathrm{p}=(0.001)$. This result implies that the TSESs at SQU had high level of MTSs. Results of Independent Sample $-\mathrm{t}$-test of differences significance in scores of OMTS items according to gender and Class standing were shown in tables 2 and 3.

Table 2.

Independent Sample - t-Test of Significance of Differences in Scores of OMTS Items according to Gender

\begin{tabular}{lccccccc}
\hline Dimension & Gender & $\mathbf{N}$ & $\mathbf{M}$ & $\mathbf{S D}$ & $\mathbf{d f}$ & $\mathbf{t}$ & $\mathbf{p}$ \\
\hline \multirow{2}{*}{ Cognitive Processes } & Male & 31 & 4.31 & 0.626 & 75 & -2.244 & 0.068 \\
& Female & 46 & 4.59 & 0.478 & & & \\
Cognitive Regulation & Male & 31 & 4.16 & 0.407 & 75 & 0.689 & 0.493 \\
& Female & 46 & 4.09 & 0.437 & & & \\
\multirow{2}{*}{ Knowledge of Cognition } & Male & 31 & 3.41 & 0.894 & 75 & -1.682 & 0.097 \\
& Female & 46 & 3.75 & 0.859 & & & \\
Total & Male & 31 & 4.12 & 0.384 & 75 & -0.995 & 0.323 \\
& Female & 46 & 4.19 & 0.271 & & & \\
\hline
\end{tabular}

Table 3.

Independent Sample - T-test of Significance of Differences in Scores of OMTS Items according to Class Standing

\begin{tabular}{lccccccc}
\hline Dimension & Class standing & $\mathbf{N}$ & $\mathbf{M}$ & $\mathbf{S D}$ & $\mathbf{d f}$ & $\mathbf{t}$ & $\mathbf{p}$ \\
\hline \multirow{2}{*}{ Cognitive Processes } & Junior & 40 & 4.26 & 0.628 & 75 & -3.970 & 0.127 \\
& Senior & 37 & 4.72 & 0.336 & & & \\
Cognitive Regulation & Junior & 40 & 4.13 & 0.464 & 75 & 0.262 & 0.794 \\
& Senior & 37 & 4.11 & 0.381 & & & \\
\multirow{2}{*}{ Knowledge of Cognition } & Junior & 40 & 3.47 & 0.733 & 75 & -1.427 & 0.158 \\
\multirow{2}{*}{ Total } & Senior & 37 & 3.76 & 1.011 & & & \\
& Junior & 40 & 4.14 & 0.244 & 75 & -0.786 & 0.434 \\
& Senior & 37 & 4.19 & 0.389 & & & \\
\hline
\end{tabular}

Findings in tables 2 and 3 revealed that there were no significant differences in MTSs in all dimensions and the total due to gender and class standing.

\section{Discussion and Conclusion}

The aim of this research was to investigate the level of MTSs among TSESs at SQU. The results indicated that the TSESs had a high level of MTSs in all dimensions of OMTS. In addition, the MTSs weren't different in gender and class standing. These results can be explained in that TSESs use the cognitive and metacognitive strategies in achieving their academic goals. The use of these strategies requires high intellectual abilities and persistence. These characteristics are often displayed in gifted people. Accordingly, gifted student teachers are capable of employing metacognitive skills in teaching more complex learning activities regardless of any gender, grade and cultural differences. Nonexistence of gender and grade differences in MTSs can be explained in that all teacher students receive the same study courses, topics and materials. This implies that the components of science teaching programs 
mainly focus on developing skills which are based on recognition and reasoning thinking. Although class standing or grade level may engender differences in the MTSs, these differences may be insignificant because of the level of study courses. Senior students receive more advanced courses compared to junior ones. However, the variance of course level is not necessarily a prerequisite of bringing about differences in cognitive and metacognitive skills. Coutinho (2006) confirmed that the high academic achievement students had a high level of MTSs. Therefore, TSESs possess self-awareness of their metacognitive processes.

They demonstrate skills to manage their metacognitive processes such as planning, monitoring and evaluation which lead them to accomplish their academic goals. In this regard, Al-Zoubi (2013) emphasized that university students with high academic achievement are mentally talented and they possess abilities to planning and selfregulation. These abilities can be evident in their MTSs. On the other hand, Fauzi and Sa'diyah (2019) stressed that the higher level of the students' metacognition, the better the awareness and management of learning they have. Young and Worrell (2018) found that knowledge of cognition and regulation of cognition had positive influence on learning outcomes. Coşkun (2018) highlighted the effectiveness of educational programs at university in developing MTSs.

The high level of MTSs among TSES in all domains of OMTS leads us to focus on the role of Department of Curriculum and Instruction in SQU. The department includes a set of components that have contributed to the development of MTSs among TSESs and non-talented students. These components included that instructors, courses, teaching strategies, assessment methods, facilities and equipment, and students. The department's science education instructors seek to develop students' cognitive thinking skills through classroom discussion based on scientific thinking skills, assigning to research and practicum activities. These theoretical and applied experiences increase self-awareness abilities and contribute to shift student thinking from cognition to metacognition. With regard to program courses, the Bachelor of Science Education program includes courses from the College of Science that provide students with specialized scientific knowledge and a deep understanding of the nature of science. In addition, the students receive courses and practicum experiences in the College of Education which contribute to the specialized professional preparation. This program holds international academic recognition from the National Science Teachers Association (NSTA), and the College of Education also held academic accreditation from Council for the Accreditation of Educator Preparation (CAEP). The program's instructors using a variety of teaching and strategies methods such as investigation, assistive technology, STEM education, micro teaching, concept map, structural learning, reflective practices, open-ended problem solving and guided discovery. In this regard, Stott and Hobden (2016) showed that learning strategies are a part of self-regulated learning that can be used with gifted learner. Selçuk (2011) indicated that learning strategy instruction was more effective than traditional instruction in improving students' achievement.

In regard to the facilities and equipment, the program is composed of various learning resources such as: computer labs, science laboratories, the Internet and equipment in the classroom. Since SQU is the only public university in Oman, admission criteria for those enrolled in the program mainly depend on the high GPA in secondary education (diploma), examinations and interviews. These admission policies contributed to joining talented students the BA program. In other words, each of bachelor's program components directly or indirectly contributing to TSESs had the MTSs in all domains of the scale. The regional and international universities also contribute to provide students with thinking and metacognitive skills. This fact was shown in previous studies (AlShawashreh et al. 2017; Al-Jarrah \& Obeidat, 2011; Al-Hamouri \& Abu Mokh, 2011; Heilat, 2017; Coşkun, 2018; Abdellah, 2015; Fares, 2018).

The positive results of the current research indicated that TSESs had high MTSs. The high academic achievement, high mental abilities, and academic programs of SQU may contribute to enrich the MTSs of TSESs. These results lead us to think deeply away from the national context in Sultanate of Oman to find a global vision of the role of universities in the development of MTSs.

There is no dispute that the university contributes to provide students with psychological and social skills. Nevertheless, development of cognitive and metacognitive processes comes at the top of the hierarchy of the required college intellectual skills. The universities must contribute to the dissemination, production and implementation of knowledge. Consequently, the traditional teaching methods used by some universities in teaching courses may constitute a barrier to develop MTSs among gifted and talented students. There are also many courses in colleges of education in universities that are offered in a theoretical manner and lack practical activities that stimulate cognitive and MTSs. Fares (2018) concluded that the traditional teaching strategies and methods used by 
colleges of education may reduce MTSs of students. In other words, the university's vision and mission must not be only limited to academic achievement, but also enhance students' thinking patterns. Therefore, Celebi and Gundogdu (2017) stressed on the university's role in developing metacognitive awareness by providing students with effective learning strategies that contribute to improve their MTSs and making them assume responsibility for their learning. To achieve this, workshops must be organized to train instructors and students in MTSs, and include these skills in various university courses (Aljaberi \& Gheith, 2015). Pramusinta et al. (2019) stated that there is an impact of discovery learning method on metacognitive and critical thinking skills more than traditional teaching methods among undergraduate. In other words, developing metacognitive abilities can contribute to make the gifted students think more systematically (Knox, 2017).

\section{Recommendations}

To sum up, it can be concluded that the TSESs had a high level of MTSs in the cognitive processes, cognitive regulation and knowledge of cognition. Components of the program- mentioned earlier- have contributed to the improvement of MTSs among TSESs. The instructors, program courses, teaching strategies, assessment methods, facilities and equipment, and students had a positive role in developing MTSs. Assessing MTSs through the selfreport scale is one of the limits of this research. Additionally, participants may not have responded to the scale objectively and transparently.

Future research should focus on exploring the relationship between metacognitive thinking and creativity or critical thinking, and the differences in MTSs among talented and non-talented science education students at SQU as well. Moreover, research should focus on investigating the impact of courses offered by college of Education and college of Science on cognitive thinking skills in the Arab context. In addition, STEM approach may be included in both colleges to become an influential factor in improving MTSs.

\section{Acknowledgments}

The researchers extend their sincere thanks and appreciation to TSESs at Department of Curriculum \& Instruction in SQU for their response on OMTS.

\section{Biodata of the Author}

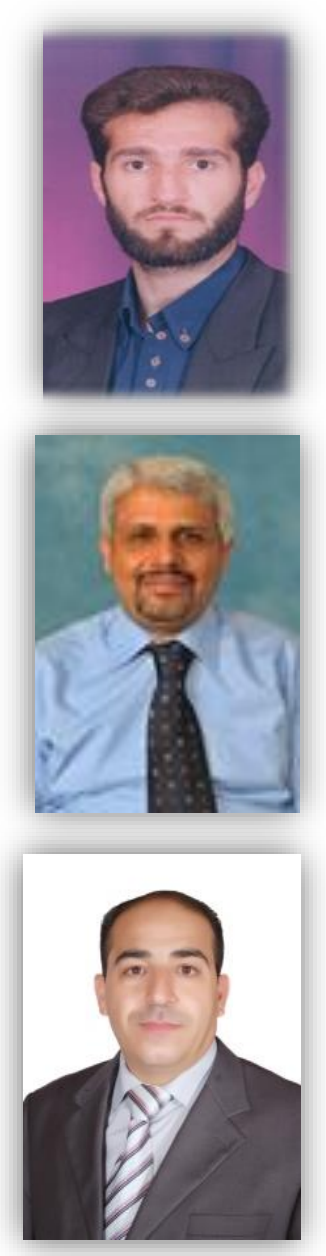

Mohammad Mahmoud Al-Gaseem is an assistant professor of science education (curriculum \& Instruction) at Sultan Qaboos University, Oman. He holds a $\mathrm{PhD}$ from Yarmouk University in Jordan. His main research focuses on modern science teaching methods, preparing science teachers, teaching science for gifted and talented students. Affiliation: Department of Curriculum and Instruction, Sultan Qaboos University, Sultanate of Oman. E-mail: mohgaseem@squ.edu.om. Phone: +9687171724327, ORCID: 0000-00031598-7322.

Bakkar Suleiman Bakkar is assistant professor of Counseling at Sultan Qaboos University, Oman. He holds a PhD in Counseling from University of Jordan. His main research interests include counseling, psychotherapy, cognitive psychology, clinical psychology and, Psychoneuroscience. Affiliation: Department of Psychology, Sultan Qaboos University, Sultanate of Oman. E-mail: bakkar@squ.edu.om. Phone +96898106636.ORCID: 00000001-5336-7912. Scopus ID: 55936909600

Suhail Mahmoud Al-Zoubi is an associate professor of special education at Sultan Qaboos University, Oman. He holds a $\mathrm{PhD}$ in special education from the University of Science Malaysia. His main research focuses on learning disabilities, ADHD, giftedness, and Academic accreditation of special education programs. Affiliation: Department of Psychology, Sultan Qaboos University, Sultanate of Oman. E-mail: smalzoubi@squ.edu.om. Phone: +96871552143. ORCID: 0000-0002- 6648-4680. SCOPUS ID: 35101436500 


\section{References}

Abdellah, R. (2015). Metacognitive awareness and its relation to academic achievement and teaching performance of pre-service female teachers in Ajman University in UAE, Procedia-Social and Behavioral Sciences, 174, 560-567.

Al-Hamouri, F., \& Abu Mokh, A. (2011). Level of the need for cognitive and metacognitive thinking among Yarmouk University students. An-Najah University Journal for Research, 25(6), 1463-1488.

Aljaberi, N., \& Gheith, E. (2015). University students' level of metacognitive thinking and their ability to solve problems. American International Journal of Contemporary Research, 5(3), 121-134.

Al-Jarrah, N., \& Obeidat A. (2011). Metacognitive thinking level among a sample of Yarmouk University Students. Jordan Journal of Educational Sciences, 7(2), 145-162.

Al-Shawashreh, O., Al-Zoubi, A., Al-Rabee, F., \& Tashtoush, Rami (2017). The relationship between metacognition and goal orientations among Yarmouk University students. Dirasat: Educational Sciences, 44 (4), 345-361.

Al-Zoubi, S. (2013). The level of metacognitive thinking among special education students. Prime Research on Education, $3(2)$, $437-$ 441.

Carr, M., \& Taasoobshirazi, G. (2008). Metacognition in the gifted: Connections to expertise. In M. F. Shaughnessy, M. V. J. Veenman \& C. Kleyn Kennedy (Eds.), Meta cognition: A recent review of research, theory and perspectives (pp. 109-125). Hauppauge: Nova Science.

Carr, M., Alexander, J., and Schwanenflugel, P. (1996). Where gifted children do and do not excel on metacognitive tasks. Roeper Review, 18(3), 212-217.

Celebi, E., \& Gundogdu, C. (2017). A study of the metacognitive awareness levels of students in Firat University's Faculty of Sports Sciences. International Journal of Learning and Teaching, 9(3), 364-369.

Coşkun, Y. (2018). A study on metacognitive thinking skills of University students. Journal of Education and Training Studies, 6(3), $38-46$.

Coutinho, S. (2006). The relationship between the need for cognition. Metacognition, and intellectual task performance. Educational Research and Reviews, 1(5), 162-164.

Efklides, A. (2006). Metacognition and affect: What can metacognitive experiences tell us about the learning process?. Educational Research Review, 1(1), 3-14.

Efklides, A. (2009). The role of metacognitive experiences in the learning process. Psicothema, 21(1), 76-82.

Everson, H., \& Tobias, S. (1998). The ability to estimate knowledge and performance in college: A metacognitive analysis. Instructional Science, 26(1-2), 65-79.

Fares, E. (2018). The degree of possession of metacognitive thinking skills of students in undergraduate psychology courses at the University of Damascus. Journal of Educational and Psychological Sciences, 19(3), 2019-257.

Fauzi, A., \& Sa'diyah, W. (2019). Students' metacognitive skills from the viewpoint of answering biological questions: Is it already good? Indonesian Journal of Science Education, 8(3), 317-327.

Heilat, M. (2017). The relationship between creative self-efficacy and metacognitive thinking among female students in the professional post graduate diploma teaching program at Abu Dhabi University. International Journal for Research in Education, $41(3), 245-279$.

Idawati., Setyosari, P., Kuswandi, D., \& Ulfa, S. (2020). The effects of problem-solving method and cognitive flexibility in improving university students' metacognitive. Journal for the Education of Gifted Young Scientists, 8(2), 657-680.

Jia X, Li, W., \& Cao L. (2019). The role of metacognitive components in creative thinking. Frontiers in Psychology, 10, 1-11.

Karaduman, G., \& Erbaş, A. (2017). Investigation of primary school teacher candidates' metacognitive awareness level. Journal for the Education of Gifted Young Scientists, 5(4), 31-48.

Knox, H.(2017). Using writing strategies in math to increase metacognitive skills for the gifted learner. Gifted Child Today, 40(1), 43-47.

Lestari, P., Ristanto, R., \& Miarsyah, M. (2019). Analysis of conceptual understanding of botany and metacognitive skill in preservice biology teacher in Indonesia. Journal for the Education of Gifted Young Scientists, 7(2), 199-214.

Louca, E. (2003). The concept and instruction of metacognition. Teacher Development, 7(1), 9-30.

Ma, A., \& Baranovich, P. (2015). Promoting self-regulation in vocabulary learning among Chinese EFL learners. A needs analysis, 24(1), 137-146.

Pramusinta, Y., Setyosari, P., Widiati, U., \& Kuswandi, D. (2019). Exploring metacognitive and critical thinking skills of preservice elementary school teachers through discovery learning method by integrating various cognitive styles. Journal for the Education of Gifted Young Scientists, 7(4), 999-1017.

Pramusinta, Y., Setyosari, P., Widiati, U., \& Kuswandi, D. (2019). Exploring metacognitive and critical thinking skills of preservice elementary school teachers through discovery learning method by integrating various cognitive styles. Journal for the Education of Gifted Young Scientists, 7(4), 999-1017.

Schraw, G. (1998). Promoting general metacognitive awareness. Instructional Science, 26(1-2), 113-125.

Schraw, G., Crippen, K., \& Hartley, K. (2006). Promoting self-regulation in science education: Metacognition as part of a broader perspective on learning. Research in Science Education, 36(1-2), 111-139.

Schwartz, B., \& Perfect, T. (2002). Introduction: Toward an applied metacognition. In T. J. Perfect \& B. L. Schwartz (Eds.), Applied metacognition (pp. 1-14). Cambridge, UK: Cambridge University Press.

Selçuk, G., Sahin, M., \& Açikgöz, K. (2011). The effects of learning strategy instruction on achievement, attitude, and achievement motivation in a physics course. Research in Science Education, 41(1), 39-62.

Stott, A., \& Hobden, P. (2016). Effective learning: A case study of the learning strategies used by a gifted high achiever in learning science. Gifted Child Quarterly, 60(1), 63-74.

Tarricone, P. (2011). The taxonomy of metacognition. NY: Psychology Press.

Tortop, H. S. (2015). A comparison of gifted and non-gifted students' self-regulation skills for science learning. Journal for the Education of Gifted Young Scientists, 3(1), 42-57. 
Ucar, F. (2018). Investigation of gifted students' epistemological beliefs, self-efficacy beliefs and use of metacognition. Journal for the Education of Gifted Young Scientists, 6(3), 1-10.

Van der Stel, M. \& Veenman, M. (2010). Development of metacognitive skillfulness: A longitudinal study. Learning and Individual Differences, 20(3), 220-224.

Van der Stel, M., \& Veenman, M. (2008). Relation between intellectual ability and metacognitive skillfulness as predictors of learning performance of young students performing tasks in different domains. Learning and Individual Differences, 18(1), 128134.

Young, A., \& Worrell, F. (2018). Comparing metacognition assessments of mathematics in academically talented students. Gifted Child Quarterly, 62(3), 259-275. 